\title{
Human Neural Precursor Cells Express Low Levels of Telomerase in Vitro and Show Diminishing Cell Proliferation with Extensive Axonal Outgrowth following Transplantation
}

\author{
Thor Ostenfeld,*,1 Maeve A. Caldwell,* Karen R. Prowse,† Maarten H. Linskens, $\dagger$ \\ Eric J auniaux, $\neq$ and Clive N. Svendsen* \\ *MRC Centre for Brain Repair, University of Cambridge, Forvie Site, Robinson Way, Cambridge CB2 2PY, United Kingdom; †Cell \\ Engineering Facility, GBB, University of Groningen, Nijenborgh 4, 9747 AG Groningen, The Netherlands; and ‡Department \\ of Obstetrics and Gynaecology, University College London, 86-96 Chenies Mews, London WC1E 6HX, United Kingdom
}

Received December 24, 1999; accepted J anuary 15, 2000

Worldwide attention is presently focused on proliferating populations of neural precursor cells as an in vitro source of tissue for neural transplantation and brain repair. However, successful neuroreconstruction is contingent upon their capacity to integrate within the host CNS and the absence of tumorigenesis. Here we show that human neural precursor cells express very low levels of telomerase at early passages (less than 20 population doublings), but that this decreases to undetectable levels at later passages. In contrast, rodent neural precursors express high levels of telomerase at both early and late passages. The human neural precursors also have telomeres (approximately $12 \mathrm{kbp}$ ) significantly shorter than those of their rodent counterparts (approximately $\mathbf{4 0} \mathbf{~ k b p}$ ). Human neural precursors were then expanded 100-fold prior to intrastriatal transplantation in a rodent model of Parkinson's disease. To establish the effects of implanted cell number on survival and integration, precursors were transplanted at either $\mathbf{2 0 0 , 0 0 0 , 1}$ million, or 2 million cells per animal. Interestingly, the smaller transplants were more likely to extend neuronal fibers and less likely to provoke immune rejection than the largest transplants in this xenograft model. Cellular proliferation continued immediately posttransplantation, but by 20 weeks there were virtually no dividing cells within any of the grafts. In contrast, fiber outgrowth increased gradually over time and often occupied the entire striatum at $\mathbf{2 0}$ weeks postgrafting. Transient expression of tyrosine hydroxylase-positive cells within the grafts was found in some animals, but this was not sustained at $\mathbf{2 0}$ weeks and had no functional effects. For Parkinson's disease, the principal aim now is to induce the dopaminergic phenotype in these cells prior to transplantation. However, given the relative safety profile for these human cells and their capacity to extend fibers into the adult rodent brain, they may pro-

${ }^{1}$ To whom correspondence should be addressed. E-mail: to212@hermes.cam.ac.uk. vide the ideal basis for the repair of other lesions of the CNS where extensive axonal outgrowth is required. ○ 2000 Academic Press

Key Words: neural precursor cells; neural progenitor cells; neural stem cells; neural transplantation; telomerase; telomeres; human; cell division; immune rejection.

\section{INTRODUCTION}

Cell loss within the CNS, acquired through trauma, disease, or aging, often results in severe disability. The replacement of lost cells would at first seem an unlikely possibility. Intrinsic neuronal connections are immensely complicated; neurons often span large distances and are forged during a period of development when the landscape of the nervous system is strikingly different from that of the adult. However, animal models have shown that when embryonic neural tissue is transplanted into the adult CNS, donor neurons survive, extend processes, and in some cases restore lost function across a wide range of disease models $(5,19$, 32, 42). Similarly, in Parkinson's disease, dopamine neurons derived from postmortem human fetal tissue often integrate successfully within the host brain and improve overall clinical rating scores (37). However, the nature of the donor tissue has evoked complex ethical and technical considerations and has led to the search for alternatives (28).

Recently, there has been a surge of interest in neural stem cells that reside within germinal zones of the developing brain and that persist within some regions of the adult CNS $(2,30,40)$. In the presence of mitogens, mixed colonies of stem cells and progenitor cells (collectively termed neural precursor cells, NPCs) can be grown for extended periods in vitro as spheroid aggregates ("neurospheres") (43). Similar cells can also be isolated from the developing human CNS (HNPCS) 
that retain the capacity to form large numbers of neurons and glia upon differentiation $(14,53,55)$. As such, they represent an obvious alternative to fresh human fetal tissue for both cell therapy and many types of in vitro studies requiring human material.

Although HNPCs can be expanded exponentially in culture, the point at which they may be expected to stop proliferating is not known. It has been proposed that the telomeres, located at the ends of vertebrate chromosomes, are crucial to the replicative capacity of many eukaryotic cells (24). Due to the inability of DNA polymerases to replicate the full length of DNA (58), telomeres shorten by between 50 to 200 nucleotides with each cell division $(1,25,63)$. Normal somatic cells, such as some human fibroblasts, can only divide a specified number of times in culture (equivalent to around 50 population doublings, PDs, the so-called "Hayflick limit") before undergoing replicative senescence $(22,27)$, and erosion of the telomeres may underlie this phenomenon $(7,13)$. The unlimited replicative potential of transformed or immortalized cells is associated with high expression levels of the ribonucleoprotein complex telomerase, which functions to stabilize and maintain telomere length with successive rounds of cell division $(15,26,35,46)$. However, the activity of this enzyme in neural stem cell populations has not been previously assessed.

A number of recent investigations have reported on the transplantation of HNPCs into the embryonic, neonatal, or adult CNS (for reviews see $(10,47,56)$. One feature of these transplants is that the cells are able to migrate and incorporate within the host nervous tissue $(11,20,21,48)$, but they rarely form large graft masses typical of primary neuronal transplants. In this study we aimed to establish (i) the telomerase activity and telomere length of cultured HNPCs, (ii) the proliferative profile of these cells in vitro and following transplantation, and (iii) the relationship between graft maturation with axonal outgrowth and the number of transplanted HNPCS.

\section{MATERIALS AND METHODS}

\section{Tissue Collection}

Human embryonic tissue (between 6 and 21 weeks postconception) was collected following routine terminations of pregnancies. The methods of collection conform with the arrangements recommended by the Polkinghorne Committee for the collection of such tissues and to the guidelines set out by the United Kingdom Department of Health.

\section{Neural Precursor Cell Cultures}

Cortical precursors from all human embryos were grown as free-floating aggregates (neurospheres) and optimal cellular expansion was achieved using novel passaging methods as previously described in detail (53). Fresh tissue was initially dissociated in trypsin and seeded at a density of 200,000 cells/ml into T75 flasks containing $20 \mathrm{ml}$ Dulbecco's modified Eagle's medium (DMEM)/HAMS-F 12 (3:1, Gibco) supplemented with penicillin G/streptomycin/amphotericin B (PSF, 1\% v/v; Gibco), B27 supplement (2\% v/v, Gibco), epidermal growth factor (EGF, $20 \mathrm{ng} / \mathrm{ml}$, Sigma), and fibroblast growth factor 2 (FGF-2, $20 \mathrm{ng} / \mathrm{ml}$, R\&D Systems) with heparin (5 $\mu \mathrm{g} / \mathrm{ml}$, Sigma). Half the growth medium was replenished on the fifth day. Passaging of cells was undertaken every 14 days by sectioning of spheres into 350- $\mu \mathrm{m}$ sections, which were reseeded into fresh growth medium at a density equivalent to 200,000 cells/ml. After the first passage all cells were grown in the presence of either EGF or FGF-2 with heparin. Leukemia inhibitory factor (LIF) has recently been shown to support the proliferation of HNPCs in vitro (14) and was added to one of the human cultures (10 ng/ml, R\&D Systems). In order to estimate cell expansion, aliquots of cells were removed from the flasks at each passage, dissociated, and counted using the trypan blue exclusion method. Cortical precursor cells derived from an 11-week-old human embryo and grown sequentially in EGF/FGF2 (14 days) and then FGF-2-containing medium (45 days) were used for in vitro differentiation and neural transplantation studies as described below. Neural precursor cells isolated from E 16 rat embryonic cortex were expanded in culture according to previously described protocols using EGF and FGF-2 as mitogens $(50,51)$.

\section{In Vitro Differentiation Studies and I mmunocytochemi stry}

For differentiation studies, whole spheres were plated directly onto poly-L-lysine (Sigma, 0.01\%)coated glass coverslips in 24-well plates (NUNC). Cultured spheres were maintained in a humidified incubator $\left(37^{\circ} \mathrm{C}, 5 \% \mathrm{CO}_{2} / 95 \%\right.$ air) in the presence of DMEM/HAMS-F 12 (3:1) supplemented with PSF (1\% $\mathrm{v} / \mathrm{v}), \mathrm{B} 27(2 \% \mathrm{v} / \mathrm{v})$, and fetal calf serum (1\% v/v). Serum was withdrawn from the medium after $24 \mathrm{~h}$. At 7 days, plated spheres were fixed in paraformaldehyde (4\% v/V in PBS, pH 7.4) and rinsed in PBS. Fixed cell cultures were blocked in $3 \%$ goat serum with $0.3 \%$ Triton X-100 and incubated with primary antibodies to either nestin (polyclonal, 1:50, kindly supplied by Dr. R. D. McKay), $\beta$-tubulin III (monoclonal, 1:500, Sigma), glial fibrillary acidic protein (GFAP, polyclonal, 1:1000, DAKO), human Ki-67 (polyclonal, 1:500, DAKO), tyrosine hydroxylase (TH, monoclonal, 1:500, Boehringer), GABA (polyclonal, 1:1000, Sigma), MAP-2ab (monoclonal, 1:50, Sigma), or human neurofilament-70 (NF-70, monocl onal, 1:500, kindly supplied by Dr. L. Sorriano). Following rinsing in PBS, the cultures were incubated in either biotinylated goat anti-mouse or fluoresceinconjugated goat anti-rabbit antibodies. Biotinylated 
cultures were visualized using a streptavidin-rhodamine conjugate, and Hoechst 33258 was used as a nuclear stain.

\section{Imaging and Quantification of Cultured Cells}

Differentiated neurosphere cultures were viewed under a Leitz DMRB fluorescent microscope and analyzed on eight replicate coverslips using a 40X objective. Quantification of cells migrating out from neurospheres was achieved by counting Hoechst-stained nuclei and specified immunoreactive phenotypes in at least four independent fields (total area, $>0.25 \mathrm{~mm}^{2}$ ) immediately adjacent to plated spheres using a predefined template. Cells double-labeled for human Ki-67 and $\beta$-tubulin III were identified by confocal microscopy (Axiovert). Using single- and dual-excitation wavelengths (488 and $564 \mathrm{~nm}$ ), serial z-axis sections were collected, analyzed, and merged to generate the final confocal images. Counts are expressed as means \pm SEM.

\section{TRAP Assay for Telomerase}

Cells were rinsed in PBS and the cell number was determined. The cell pellet was then resuspended in Chaps Iysis buffer (10 mM Tris- $\mathrm{Cl}, \mathrm{pH}$ 7.5, $1 \mathrm{mM}$ $\mathrm{MgCl}$, $1 \mathrm{mM}$ EGTA, $0.1 \mathrm{mM}$ phenlymethylsulfonyl fluoride, $5 \mathrm{mM} \beta$-mercaptoethanol, 0.5\% Chaps, $10 \%$ glycerol) using $50 \mu \mathrm{l}$ of lysis buffer per $10^{6}$ cells and placed on ice for $30 \mathrm{~min}$. Samples were microcentrifuged at $12,000 \mathrm{~g}$ for $30 \mathrm{~min}$ at $4^{\circ} \mathrm{C}$. A Coomassie assay (Bio-Rad) was used to quantitate the amount of protein in each extract and TRAP assays were performed as described previously (35) with the following modifications. An aliquot of the extract was incubated with 100 ng of the TS oligo (5'-AATCCGTCGAGCAGAGTT-3') buffer, $50 \mu \mathrm{M}$ dNTPs, $1 \mathrm{U}$ Taq polymerase, and $0.4 \mu \mathrm{l}$

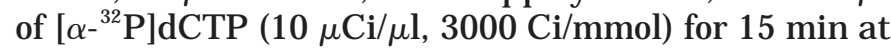
room temperature. The tubes were then transferred to a thermal cycler and heated for $10 \mathrm{~min}$ at $94^{\circ} \mathrm{C}$ before adding $100 \mathrm{ng}$ of the $\mathrm{CX}$ primer (5'-CCCTTACCCTTACCCTTACCCTAA-3'). After 27 cycles of $94^{\circ} \mathrm{C}$ for $30 \mathrm{~s}, 50^{\circ} \mathrm{C}$ for $30 \mathrm{~s}$, and $72^{\circ} \mathrm{C}$ for $30 \mathrm{~s}$, half the reaction was analyzed by electrophoresis in $0.6 \times$ TBE in $10 \%$ polyacrylamide nondenaturing gels, and the gels were exposed to a Phosphorl mager plate. The GLC4 human lung cancer cell line was used as internal standard (35).

\section{Terminal Restriction Fragment (TRF) Length} Analysis

Genomic DNA was prepared from cell pellets according to a standard protocol (16). Briefly, cells were resuspended in $100 \mu \mathrm{l}$ of $1 \times \mathrm{TE}$, added to $1 \mathrm{ml}$ of DNA extraction buffer (100 mM NaCl, $10 \mathrm{mM}$ Tris, $25 \mathrm{mM}$ EDTA, pH 8, 0.5\% SDS, $0.1 \mathrm{mg} / \mathrm{ml}$ proteinase $\mathrm{K}$ ), and digested at $50^{\circ} \mathrm{C}$ for $16 \mathrm{~h}$. The cell lysate was then treated as described previously (16). DNA was dissolved in $1 \times \mathrm{TE}$ and heated at $50-55^{\circ} \mathrm{C}$ for $1 \mathrm{~h}$. An aliquot (3-5 $\mu \mathrm{g}$ ) of DNA was digested with HinF 1/Rsal ( 2 units each per $\mu \mathrm{g}$ of DNA) and DNase-free RNase at $37^{\circ} \mathrm{C}$ for $16 \mathrm{~h}$. Aliquots (1-2 $\left.\mu \mathrm{g}\right)$ of digested DNA were separated on $0.5 \%$ agarose gels in $1 \times$ TBE. The gels were dried for $30 \mathrm{~min}$ at $60^{\circ} \mathrm{C}$, denatured $(0.5 \mathrm{M} \mathrm{NaOH}$, $1.5 \mathrm{M} \mathrm{NaCl}$ ) for $15 \mathrm{~min}$, and neutralized (0.5 M Tris $(\mathrm{pH} 7), 1.5 \mathrm{M} \mathrm{NaCl}$ ) for $15 \mathrm{~min}$. Gels were prehybridized in $50 \mathrm{ml}$ of Church and Gilbert hybridization soIution at $37^{\circ} \mathrm{C}$ for $1 \mathrm{~h}$. An aliquot $(0.25 \mu \mathrm{g})$ of a singlestranded telomeric oligonucleotide, (TTAGGG) $)_{3}$, was end-labeled with $50 \mu \mathrm{Ci}$ of $\left[\gamma^{-32} \mathrm{P}\right] \mathrm{ATP}$ and $10 \mathrm{U}$ of T4 polynucleotide kinase and added to the prehybridization buffer. The gels were incubated at $37^{\circ} \mathrm{C}$ for $16 \mathrm{~h}$ and washed with $0.5 \times \mathrm{SSC}, 0.1 \% \mathrm{SDS}$ at $37^{\circ} \mathrm{C}(3 \times 10$ min). To determine the TRF length, a Phosphorimager (Molecular Dynamics) was used to quantitate the position and strength of the radioactive signal in each of the lanes as described.

\section{Lesion Surgery and Behavioral Evaluation}

Sixty adult female Sprague-Dawley rats (190-240 g, Charles River, UK) were housed in groups of five in our animal facility at a constant temperature and light: dark (12:12 h) cycle with free access to food and water. Surgical and experimental procedures were carried out in strict accordance with UK Home Office regulations. All rats received unilateral lesions of the ascending nigrostriatal dopaminergic pathway under anesthetic. Ster eotaxic lesions were performed by injection of 6-hydroxydopamine (6-OHDA, $12 \mu \mathrm{g})$ at one site in the medial forebrain bundle as described previously (48). The efficacy of the lesion was assessed at 2 weeks by quantification of motor asymmetry following administration of metamphetamine $\mathrm{HCl}(5 \mathrm{mg} / \mathrm{kg}$ ip). Rats with a net rotational asymmetry of at least 7 turns per minute were included in the transplantation study. Animals with 6-OHDA lesions were divided into 12 groups ( $n=5$ per group) where the mean rotation score per group was 11 turns per minute.

\section{Cell Preparation and Transplantation Surgery}

Groups of rats were stratified to receive intrastriatal neural precursor cell transplants at a cell density equivalent to approximately 200,000 cells per graft ( $n=3$ groups), 1 million cells per graft ( $n=3$ groups), or 2 million cells per graft ( $n=3$ groups). Twenty-four hours prior to surgery human neural precursor cells grown as neurospheres were prepared by passaging into 350- $\mu \mathrm{m}$ sections followed by resuspension in fresh growth medium. The sections rounded up overnight to form small spheres. In order to estimate cell numbers, spheres from each T75 flask were resuspended in $2 \mathrm{ml}$ of growth medium and three 100- $\mu$ l aliquots were re moved for treatment with trypsin and subsequent dissociation. Cell viability was assessed by trypan blue 
exclusion. The number of cells within the aliquots was used to estimate total cells per milliliter for the flask and enabled the removal of further aliquots containing the appropriate number of spheres for grafting. This method maintained cells as spheres for transplantation rather than as a dissociated cell suspension. Aliquots of spheres were prepared individually for each animal immediately prior to transplantation. For grafting, spheres were resuspended in $5 \mu \mathrm{l}$ DMEM/ B27-supplemented medium and loaded into a $5 \mu$ l zerodead volume, plunger-in-the-needle SGE glass microsyringe incorporating a 30-gauge stainless steel blunt cannula (Fisher Scientific, UK). Injections were made into the left striatum at the following coordinates: $A P=+0.5 \mathrm{~mm} ; \mathrm{L}=+3.0 \mathrm{~mm}$ from bregma, and $\mathrm{V}=-4.5 \mathrm{~mm}$ from dura; the toothbar was set at -2.5 $\mathrm{mm}$. A further three groups of animals received sham grafts. All animals were immunosuppressed by treatment with cyclosporin A (10 mg/kg, ip, Sandoz) for 2 days prior to transplantation and for the entire duration of the experiment. Assessments of motor asymmetry as described were made at 2, 5, 10, 15, and 20 weeks following transplantation. At 2, 6, and 20 weeks following grafting, five animals from each transplant group were terminally anesthetized and their brains fixed for immunohistochemical processing by transcardial perfusion with $0.1 \mathrm{M}$ PBS followed by $4 \%$ paraformaldehyde in $0.1 \mathrm{M}$ phosphate buffer.

\section{I mmunochemistry and I mmunohistochemistry}

Fixed brains were equilibrated in $30 \%$ sucrose for $48 \mathrm{~h}$ and then cut into $60-\mu \mathrm{m}$ coronal sections on a freezing microtome. Endogenous hydrogen peroxidase activity was quenched by treating sections with $10 \%$ hydrogen peroxide in 10\% methanol for $5 \mathrm{~min}$. For each primary antibody, a one in six series of sections was then blocked in 3\% goat serum with $0.3 \%$ Triton X-100 and subsequently incubated for $48 \mathrm{~h}\left(4^{\circ} \mathrm{C}\right)$ with antibodies to human Ki-67 (Dako, polyclonal, 1:100), human NF-70 (monoclonal, 1:500), human glutathione S-transferase (GST $\pi$; Biotrin, polyclonal, 1:200), human GFAP (Sternberger Monoclonals, monoclonal, 1:1000), TH (J acques Boy, France, polyclonal, 1:4000), or rat CD8 (Serotec, monoclonal, 1:750). Sections were washed in TBS and then incubated in the appropriate secondary antibodies: either biotinylated goat antimouse (Vector Labs, rat preadsorbed, 1:200) or biotinylated goat anti-rabbit (Dako, 1:200). Following further rinses in TBS, sections were transferred to an avidin- biotin complex (Vectastain ABC kit, Vector Labs) in TBS for $1 \mathrm{~h}$. Antigens were subsequently visualized using 3,3'-diaminobenzidine as chromagen. Control sections were included in the analysis following omission of the primary antibody. Further controls for the human selective antibodies consisted of animals, which had received similar grafts of rat or mouse precursor cells. No cells immunoreactive for NF-70 or
Ki-67 were seen in any animals receiving nonhuman grafts at 20 weeks post-transplantation. For Nissl staining, a further one in six series of sections was mounted on gelatinized slides, delipified, and stained with cresyl violet $(0.5 \%, 20 \mathrm{~min})$ as previously described (48).

\section{Quantitative Analyses}

Analysis of graft size, cell numbers, and fiber densities was performed by experimenters "blinded" to the identity of the samples. Graft area was determined on each section by capturing an image at $\times 20$ magnification on a Seescan image analyzer (Seescan, Inc., UK) and tracing around the entire graft defined by cresyl violet staining. Graft volumes were calculated by multiplying the sum of the cross-sectional areas by the section thickness $(60 \mu \mathrm{m})$ and by a factor of six. Quantification of Ki-67-positive cells within grafts was achieved using an Olympus C.A.S.T grid stereology system (version 1.09; Olympus, Denmark). A standard stereological method (59) was used to express Ki-67positive cell counts per unit volume of graft. The density of NF-70-immunoreactive fibers was estimated in two sections representative of each graft using an optical grid and a dark-field condenser. For each section, four predefined areas (total area, $0.25 \mathrm{~mm}^{2}$ ) in the striatum immediately adjacent to the graft were divided into 20 squares, and the number of fibers crossing into each square was determined under a 40X objective. The result is a relative measure of neurite outgrowth expressed per square millimeter of striatum. Statistical analyses were performed using a twoway ANOVA (Prism, v.3, GraphPad, CA). All data are expressed as means \pm SEM.

\section{RESULTS}

\section{HNPCs Generate a High Proportion of Neurons in Vitro}

We first aimed to establish the differentiation profile of HNPCs in vitro. Precursor cells derived from human embryonic cortex underwent proliferation as neurospheres and were seen to express the intermediate neurofilament nestin as we have previously reported (53). After approximately eight population doublings (PDs) over a 60-day period in the presence of FGF-2 (Fig. 1a), the mitogen was withdrawn and whole spheres were allowed to differentiate. Cells were seen to migrate out from the plated spheres and by 7 days had formed a dense monolayer of $\beta$-tubulin III-positive neurons (Fig. 1b) and GFAP-positive astrocytes (not shown) in agreement with our previous investigations (53). More than half of these migrating cells (57 \pm 3.5\%; $n=8$ spheres) expressed a neuronal phenotype. Here, we also show that a small percentage of cells were still capable of division at 7 days following mito- 


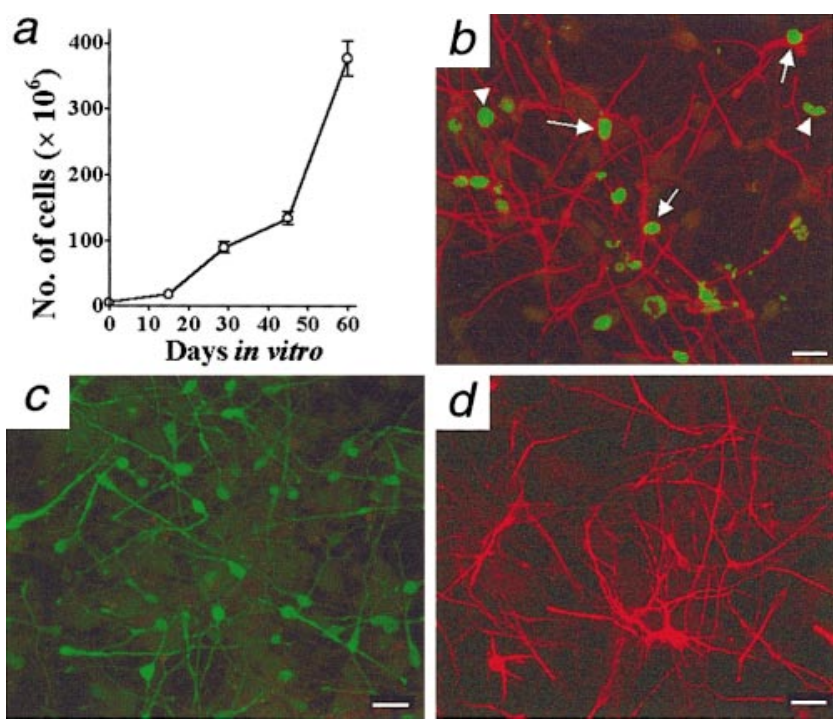

FIG. 1. In vitro growth (a) and differentiation (b- d) of human neural precursor cells. Cells for neural transplantation were grown as neurospheres sequentially in EGF/FGF-2 (14 days) and then FGF-2-containing culture medium (45 days). After 60 days, an estimated 100-fold expansion was achieved (a), consistent with approximately 3.2 population doublings with every passage. (b) Confocal micrograph at 7 days following whole sphere differentiation in vitro showing the emergence of $\beta$-tubulin III-positive neurons (red) and proliferating cells expressing human $\mathrm{Ki}-67$ (green); dividing neuronal progenitor cells coexpressed $\beta$-tubulin-III and Ki-67 (arrows) and could be distinguished from dividing nonneuronal phenotypes (arrowheads). The majority of the differentiated neurons expressed GABA (c); no TH-immunoreactive cells were detected. At this stage, many neurons expressed the mature neuronal marker Map-2ab (d) and, to a lesser extent, human neurofilament-70 (not shown). Scale bars, $30 \mu \mathrm{m}$.

gen withdrawal and that $4.9 \pm 1.3 \%$ of the total emerging cell population expressed the human-specific proliferation marker Ki-67 (Fig. 1b). At the same time point, $2.6 \pm 0.7 \%$ of the $\beta$-tubulin III-positive neurons were also immunoreactive for $\mathrm{Ki}-67$, indicating that migrating human neuronal precursors are capable of division. By 7 days, the majority of differentiating neurons were immunoreactive for GABA (Fig. 1c), although no cells were seen to be expressing $\mathrm{TH}$ (not shown). At this stage of differentiation, many cells also showed immunoreactivity for the mature neuronal marker MAP-2ab (Fig. 1d) and weak expression of human NF-70 (not shown).

\section{Telomerase Is Present at Early, but Not Late Passages}

At early PDs all human cultures expressed very low levels of telomerase, which was approximately 50-fold less than that seen in the human lung carcinoma cell line GLC4 (Figs. 2a and 2b, Table 1). I n order to assess whether telomerase activity remained at this low level at later passages, a number of cultures were followed up to 35 PDs. At 21 PDs or more, no detectable telomerase activity could be found in any of the human NPCS analyzed (Fig. 2b) suggesting complete downregulation of this enzyme. To establish how this compared to rodent tissues, neurospheres were generated from the cortex of E16 rat embryos and expanded in culture using a combination of EGF and FGF-2 as mitogens. Following 2 weeks of rapid proliferation, equivalent to approximately 6 PDs in vitro, these rat cultures were found to express high levels of telomerase (Fig. 1a). This expression was approximately twofold less than that seen in the GLC4 cells and an order of magnitude greater than that found for the human cells (Figs. 2a and $2 b$, Table 1 ). Rat NPCs were also assayed for tel omerase at 6 weeks of growth, the maximum attainable for these cells before the cultures undergo senescence (51). At this time, telomerase expression was not significantly different from that seen at earlier passages (not shown).

In order to examine further the differences between rodent and human NPCs, and to investigate for possible tel omere shortening with extended time in culture, TRF length analysis was undertaken. Rat telomeres were greater than $27 \mathrm{kbp}$ in length after 6 PDs. In contrast, human telomeres, after an equivalent number of PDs in culture, were significantly shorter at approximately 12 kbps (Fig. 2c, Table 1), in agreement with previous studies describing differences between rodent and human TRF lengths (64). There was no significant correlation between telomere length and the number of PDs, which may reflect interembryonic differences in the starting lengths of the telomeres from individual embryos. However, one culture $(\mathrm{H} 2)$ was serially assessed at 7 and 18 population doublings and showed a decline in telomere length from 12.33 to $10.66 \mathrm{kbp}$. Furthermore, the oldest embryo (H5), with the greatest number of PDs, had the shortest telomeres (Fig. 2c and Table 1). Thus, these data are consistent with a trend toward telomere shortening with time in vitro. In keeping with these findings, none of the propagated human cultures were sustainable beyond 40-50 population doublings (not shown).

\section{Division of Cells within HNPC Grafts Only Occurs during the First Few Weeks}

Following transplantation of whole neurospheres into the 6-OHDA-lesioned striatum, distinct grafts were seen at all three time points studied: 2 weeks $(n=15), 6$ weeks $(n=14)$, and 20 weeks $(n=15)$ post-transplantation (Figs. 3a-3c). No discernible graft masses were found in sham-treated animals $(n=15)$. There was a direct relationship between the number of transplanted cells and graft volume (Fig. 3d). There was also a nonsignificant trend toward an increase in graft size with time, such that by 20 weeks graft volumes were approximately twice those seen at 2 weeks (Fig. 3d). In order to establish whether grafted HNPCs continued to proliferate following transplantation, we used immunohistochemical analysis with the human- 


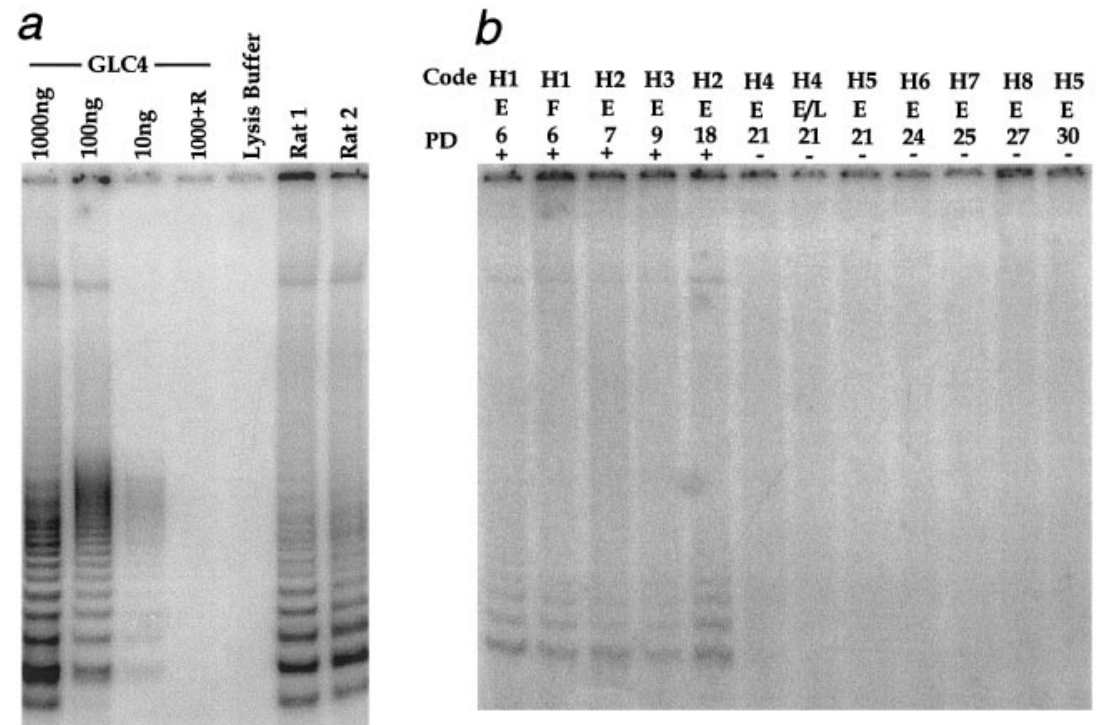

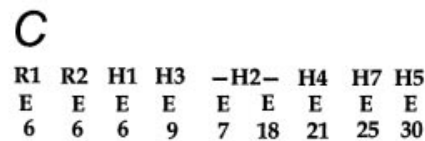

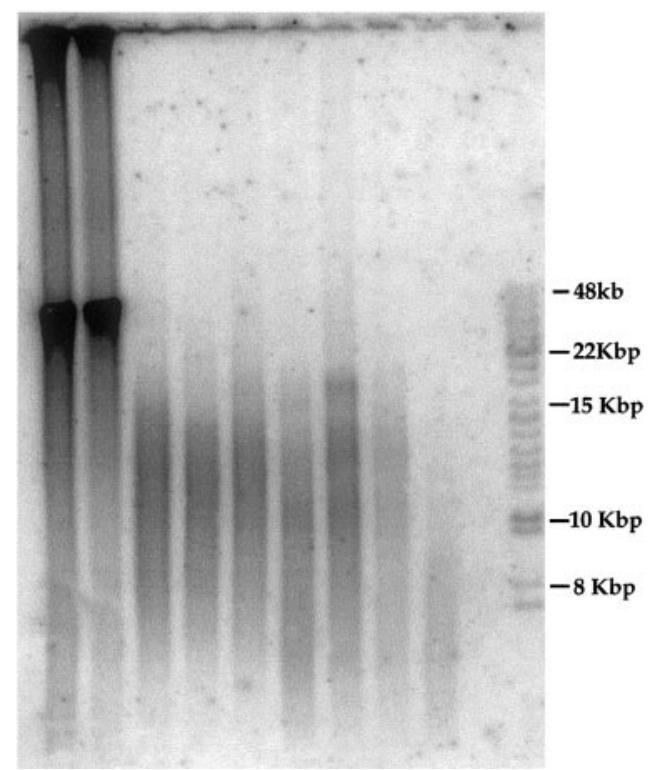

FIG. 2. TRAP assays for telomerase (a, b) and telomere restriction fragment (TRF) length analysis (c) in expanded neural precursor cells derived from individual human (H1-H8) or rat embryos (R1, R2). The standard comprised a telomerase-expressing human lung carcinoma cell line GLC4 (1000, 100, 10 ng per assay). Lysis buffer or GLC4 cell extract treated with RNase (GLC4 + R) was used as negative control. Sample quantity: $1 \mu \mathrm{g}(\mathrm{R} 1, \mathrm{R} 2)$ or $5 \mu \mathrm{g}(\mathrm{H} 1-\mathrm{H} 8)$ per assay. After 6 population doublings (PDs), telomerase levels in rat neural precursor cells were $50 \%$ of those seen with 1000 ng GLC4 cells (a). At early passages (up to 18 PDs), both EGF (E) and FGF-2 (F)-responsive human neural precursors expressed low levels of telomerase (approximately $2 \%$ of levels in $1000 \mathrm{ng}$ GLC4) (b). At later passages, telomerase activity was negligible in all of the human cultures studied. The presence of LIF (L) in one human culture (H4) had no effect on telomerase expression. After 6 PDs, mean TRF length for the rat precursors was $27 \mathrm{kbp}$ compared to $12 \mathrm{kbp}$ for the human precursors (c). TRF length analysis across all human embryos suggested a trend toward telomere shortening with increasing duration in culture.

specific proliferation marker $\mathrm{Ki}-67$. This revealed that a number of transplanted cells within the grafts were mitotically active at 2 weeks (Fig. 3e). At 6 weeks, $\mathrm{Ki}$-67-positive cells were seen in the striatum, indicating that HNPCs were migrating out from the graft (Fig. 3f). Cell proliferation within all transplants declined significantly over time such that by 20 weeks less than $0.3 \%$ of the cells were dividing ( $\mathrm{Fig}$. 3h). Thus the trend toward increased graft volume was not associated with continuing cell proliferation, but was more likely due to limited migration of cells away from the graft core and a thinning out of the transplant (Figs. 3a-3d).

\section{Fiber Outgrowth from the HNPC Transplants} Increased over a 5-Month Period

Neuronal fiber outgrowth from HNPC grafts has previously been shown to be modest at best $(21,48,55)$. Using a human and pig-specific marker of neurofilament we next established the extent to which fiber outgrowth occurred from these transplants and what effects graft size may have on this. In marked contrast to the Ki-67 data, immunoreactivity for human NF-70 revealed an overall increase in the emergence and out- growth of neuronal fibers from the grafts over a 5-month period (Figs. 3i-3l and Fig. 4). By 20 weeks, large numbers of NF-70-positive fibers were observed in four out of five low-density grafts, in three out of five intermediate-density grafts, and in none of the five high-density grafts. In two of the intermediate-density grafts fibers were seen to cross into white matter tracts in the ipsilateral and contralateral corpus callosum (Figs. 4b and 4c) and al so to extend over long distances into several grey matter regions. These included the prepiriform cortex, amygdala, lateral septum, and ventral mesencephal on. (Figs. 4d-4h). For those grafts not exhibiting any evidence of fiber outgrowth at 20 weeks, we noticed histological changes consistent with a hostderived cell-mediated immunol ogical response directed against the xenograft. In the most florid cases this was indicated by widespread perivascular cellular infiltrates, hypercellularity in the peripheral regions of the graft and adjacent striatum, and distortion of the normal striatal architecture. In order to investigate this further we conducted immunohistochemistry for rat CD8 T-lymphocytes (Figs. 5a and $5 \mathrm{~b}$ ) and matched the extent of the cellular distribution with the emergence of NF-70-positive fibers from the corresponding ani- 
TABLE 1

Levels of Telomerase Activity and Mean Telomere Restriction Fragment (TRF) Lengths for Expanded Human Neural Precursor Cells Derived from Individual Human (H1-H8) or Rat Embryos

\begin{tabular}{|c|c|c|c|c|c|}
\hline Code & Embryo age & Growth factor & PD & $\begin{array}{c}\text { Telomerase activity } \\
(\% \text { GLC } 4)\end{array}$ & $\begin{array}{l}\text { TRF length } \\
\text { (kbp) }\end{array}$ \\
\hline GLC4 & Cell line & Serum & - & 100 & - \\
\hline GLC4 + RNase & Cell line & Serum & - & 0 & - \\
\hline Rat1 & E16 & $\mathrm{EGF}+\mathrm{FGF}$ & 6 & 45 & 26.19 \\
\hline Rat2 & E16 & $\mathrm{EGF}+\mathrm{FGF}$ & 6 & 47 & 28.04 \\
\hline $\mathrm{H} 1$ & 8 weeks & FGF & 6 & 2.9 & - \\
\hline $\mathrm{HI}$ & 8 weeks & EGF & 6 & 2.5 & 12.30 \\
\hline $\mathrm{H} 2$ & 8 weeks & EGF & 7 & 3.2 & $12.23^{\mathrm{a}}$ \\
\hline H3 & 10 weeks & $\mathrm{EGF}$ & 9 & 1.9 & 11.49 \\
\hline $\mathrm{H} 2$ & 8 weeks & EGF & 18 & 4.0 & $10.66^{\mathrm{a}}$ \\
\hline $\mathrm{H} 4$ & 9 weeks & EGF & 21 & 1.8 & 12.43 \\
\hline $\mathrm{H} 4$ & 9 weeks & $E G F+L I F$ & 21 & 0.7 & - \\
\hline H5 & 21 weeks & EGF & 21 & 0.2 & - \\
\hline H6 & 15 weeks & EGF & 24 & 0.2 & - \\
\hline $\mathrm{H} 7$ & 11 weeks & EGF & 25 & 0.1 & 11.84 \\
\hline $\mathrm{H} 8$ & 7 weeks & EGF & 27 & 1.0 & - \\
\hline H5 & 21 weeks & EGF & 30 & 0.1 & 8.53 \\
\hline
\end{tabular}

Note Human cultures are listed in order of population doublings (PDs). Telomerase activities are corrected for sample size and expressed as percentage of that for GLC4 cells (\% GLC4 = pixel volume of sample lanes - background $\times 100 /$ pixel volume of GLC4 1- $\mu \mathrm{g}$ sample). Telomerase product bands were not visible at values less than $1.9 \%$ GLC4.

${ }^{a}$ Denotes serial assessment of TRF lengths at 7 and 18 PDs for human culture $\mathrm{H} 2$.

mals (Figs. $5 \mathrm{c}$ and $5 \mathrm{~d}$ ). For all animals, we were able to establish an inverse relationship between the emergence of human neuronal fibers and the extent of the host Iymphocytic infiltrate. It was notable that those brains showing the most florid signs of xenograft rejection had been recipients of high-density transplants ( 2 million cells) and that only one out of five of these grafts were positive for NF-70 at 20 weeks (Figs. 3l, 5a, and $5 c$ ). In contrast, those grafts giving rise to extensive fiber outgrowth were negative for rat CD8 T-lymphocytes (Figs. $5 b$ and $5 d$ ).

\section{Human HNPCs Do Not Spontaneously Give Rise to Large Numbers of TH Neurons}

Immunohistochemistry conducted for human-GST $\pi$ (Fig. 5e) and for human-GFAP (Fig. 5f) revealed that transplanted human precursor cells and precursor-derived astrocytes, respectively, were capable of migrating widely throughout the striatum and along adjacent white matter tracts in the internal capsule, corpus callosum, and anterior commissure. This is consistent with our earlier studies $(48,49)$. A substantial fraction of these cells were also found to have migrated into the contralateral striatum and pallidum. For all animals included in this study, complete 6-OHDA lesions of the nigrostriatal system were confirmed by immunohistochemical analysis for TH in the substantia nigra, ventral tegmental area, and striatum. None of these animals showed behavioral recovery following grafting of human neural precursors when tested for motor asymmetry at any time point (not shown). However, at 6 weeks, transient TH expression was seen in a small number of cells within three of the low-density transplants and in one of the intermediate-density transplants (Fig. $5 \mathrm{~g}$ ). TH-immunoreactive fibers arising from these cells were al most exclusively confined to the grafts.

\section{DISCUSSION}

Human stem cells may provide a source of tissue for many types of cell-based therapy in the management of neurol ogical disease $(47,52,55,56)$. However, several issues need to be addressed before clinical trials should be undertaken. Foremost among these are issues pertaining to safety along with their capacity to establish efferent neuronal connections within the host tissue and the functional effects of such transplants.

\section{Telomeres and Telomerase in HNPCs}

Self-renewing pluripotent cells derived from the human blastocyst, and which resemble embryonic stem (ES) cells, express significant levels of telomerase (54), as do the majority of human tumors and immortalized cell lines $(26,35,46)$. Furthermore, normal human skin fibroblasts and retinal pigment epithelial (RPE) cells, when genetically modified to overexpress telomerase, are capable of breaking through the Hayflick limit and will continue to divide for as long as 80 PDs or more (7). One previous report has shown that primary human brain cells, from either the embryo or adult, express little or no telomerase (1). That study also failed to detect a significant correlation between telomere length in brain cells and the age of the donor 

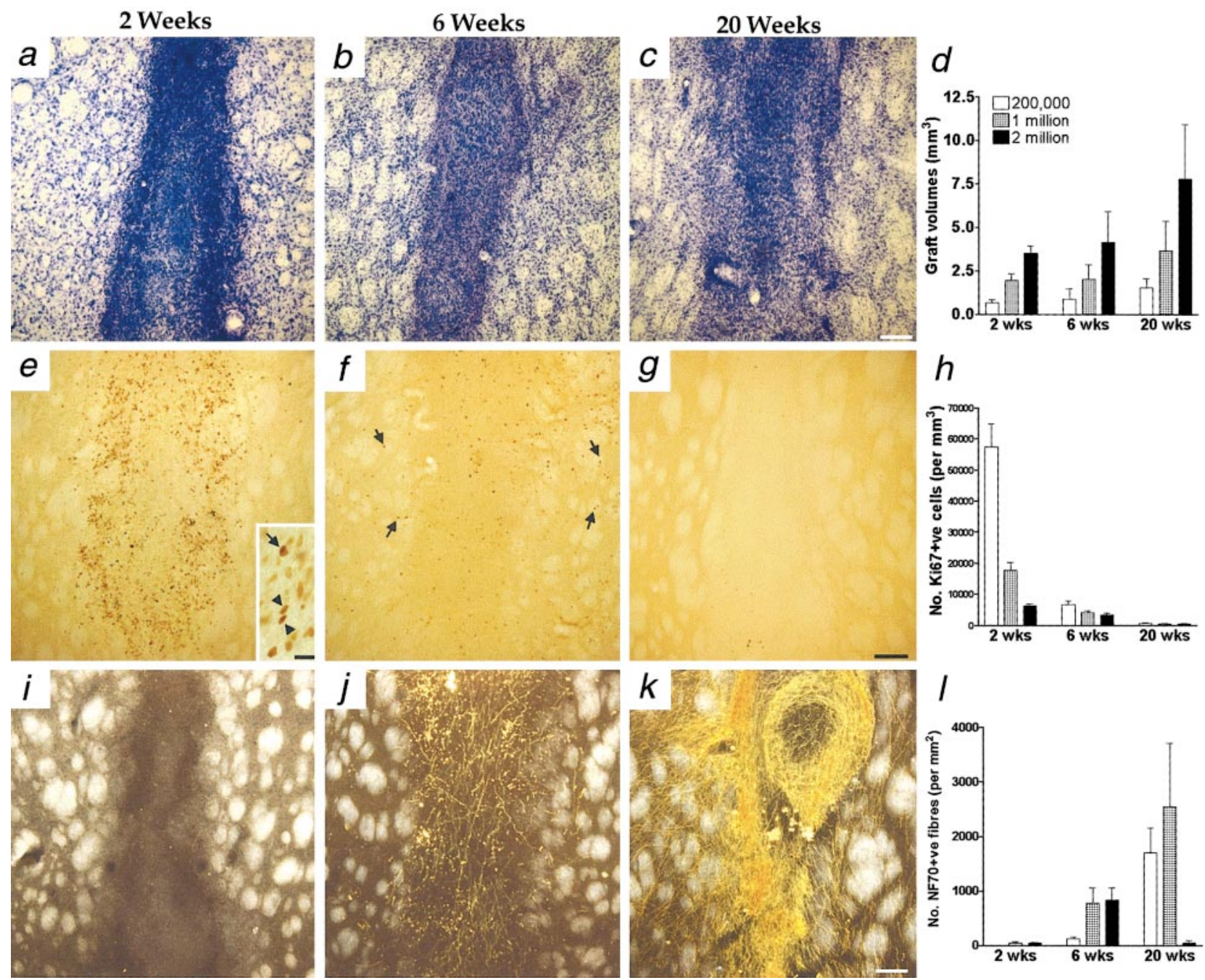

FIG. 3. Development of human neural precursor grafts over 20 weeks following whole neurosphere transplantation into the 6-OHDAlesioned striatum. Photomicrographs are representative of intermediate density grafts (equivalent to 1 million cells) at 2,6 , and 20 weeks. Discrete graft masses were seen at all three time points ( $a, b, c)$. A direct relationship between transplanted cell density and measured graft volume was noted (two-way ANOVA, $\mathrm{P}<0.01$, density effect) along with a trend toward increased graft size with time across all densities (d). Many cells expressed the human proliferation marker $\mathrm{Ki}-67$ at early time points (e), and there was a significant inverse relationship between graft density and the number of dividing cells (h) (two-way ANOVA, P $<0.001$ ). Inset (e) shows high-power view of Ki-67-positive cell (arrow) and daughter cells postdivision (arrowhead). By 6 weeks some migrating human precursors were also seen to be dividing in the striatum (arrows) (f). For all densities, the number of Ki-67-immunoreactive cells diminished to negligible levels by 20 weeks (g, h) (two-way ANOVA, $\mathrm{P}<0.001$ ). In contrast, there was an overall increase in the emergence and outgrowth of human NF-70-immunoreactive neuronal fibers with time (two-way ANOVA, P $<0.001$ ), which was most extensive for the intermediate density grafts (i-I). Scale bars, $130 \mu \mathrm{m}$; inset to (e), $15 \mu \mathrm{m}$.

tissue, perhaps suggesting that differences between the starting length of telomeres between samples may have obscured any overall decline in length. However, the same study did not address the issue of telomerase expression in purified cultures of human precursor cells. Here we have shown that expanded populations of HNPCs in culture express very low levels of telomerase when compared with similar rodent cultures and that this declines to undetectable levels by 20 PDs. The low levels seen at early passages may represent very low expression of the enzyme in all of the cells; alternatively, it may be indicative of a small proportion of cells (perhaps a true multipotent stem cell population) expressing very high levels of telomerase that are then lost at later passages). Single cell assays for telomerase activity are currently being undertaken to determine this. If one assumes that only a minority of cells within the cultures are true stem cells, and if these are lost over time, then later passage cultures may be composed of mainly bipotent astrocytic-neuronal progenitors rather than stem cells; indeed, such a scenario would explain the very low numbers of oligodendrocytes seen to spontaneously differentiate under these conditions $(14,53)$. However, even the low levels of telomerase expression seen at early passages may be insufficient to prevent telomere erosion, as reported 

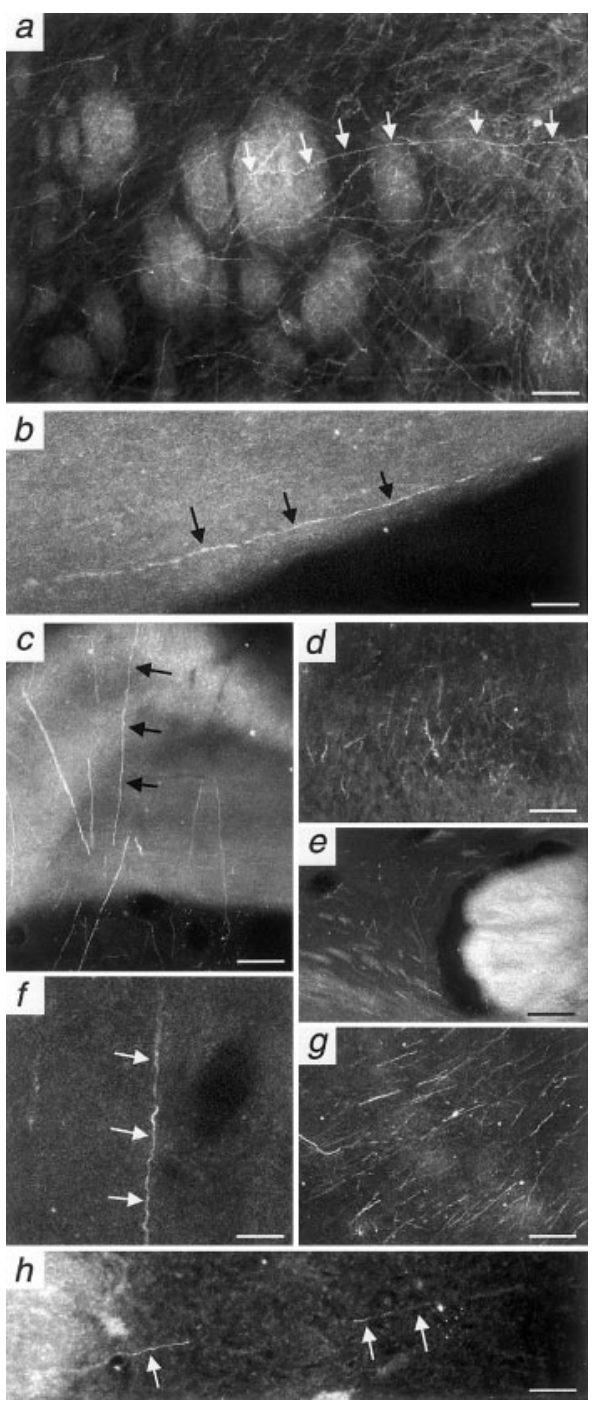

FIG. 4. Dark-fiel d photomicrographs showing human NF-70-positive fibers emerging from intermediate density grafts (1 million cells) at 20 weeks. Extensive fiber outgrowth shown in the striatum (a). Neuronal fibers crossing into white matter tracts of the corpus callosum (contralateral hemisphere, b; ipsilateral hemisphere c). Neuronal fibers in grey matter regions: prepiriform cortex (d), ventral striatum adjacent to anterior commisure (e), lateral septum (f), amygdala (g) and ventral mesencephalon (h). Long axons are indicated (arrows). Scale bars: $100 \mu \mathrm{m}$ (a-g), $50 \mu \mathrm{m}(\mathrm{h})$.

recently following the forced expression of telomerase in human fibroblasts and RPE cells (7). Interestingly, parallel rat neural precursor cultures expressed high levels of telomerase and possess telomeres that are twice as long as those seen in the human cells. This is in agreement with other reports comparing rodent and human tissues (64) and might underlie the observation that rodent cells are more susceptible to transformation in culture than human cells (23). The rat cells divide at a much faster rate than the human cells (almost every $24 \mathrm{~h}$ compared to every 8 days) and enter senescence after 5 weeks in culture (51), suggesting that even in the presence of telomerase alternative intrinsic regulatory mechanisms operate to count rodent cell divisions.

TRF length analysis strongly suggests, but does not demonstrate conclusively, that telomere length decreases as a function of the number of PDs in culture. Due to the nature of human embryonic tissue collection it was difficult to generate the appropriate cultures for these experiments. However, one human culture, serially assayed at 7 and 18 PDs, showed a large decline in telomere length consistent with a loss of approximately 150 bp per division. Furthermore, our oldest culture had the shortest telomeres. Therefore, we suggest that telomere shortening is very likely to be occurring in these cultures. The fact that the HNPCs described here are limited to 40-50 PDs may seem to be a disadvantage if they are to be used for the generation of neural tissue in vitro. However, 31 population doublings is equivalent to a one-billion-fold increase in total cell number. With a starting population of one million precursors, this would generate $10^{15}$ cells. As these precursors can be frozen and stored while retaining the capacity to produce neurons $(14,53)$, it would therefore be possible to generate complete cell banks from one embryo. On an equally important note, the lack of telomerase in these cells suggests a reduced likelihood of cell transformation.

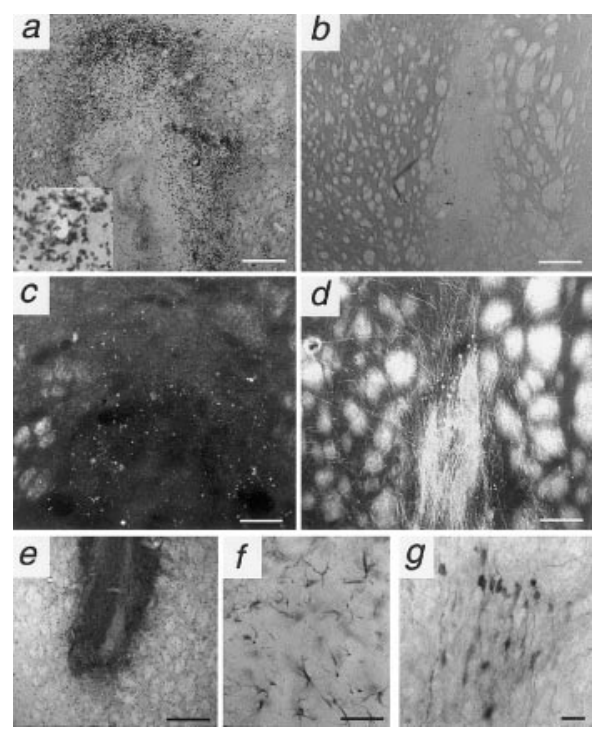

FIG. 5. I mmunohistochemistry conducted for rat CD8 T-Iymphocytes $(a, b)$ and for human NF-70 (c, d). High-density grafts (2 million cells; a and c, equivalent sections shown from the same recipient) invariably provoked a fulminant host-derived T cell-mediated immune response, which was not seen in low-density grafts $(200,000$ cells; b and d, equivalent sections shown). Inset (a) shows infiltrating perivascular Iymphocytes. Intrastriatal graft mass defined by human GST $\pi$ immunoreactivity at 20 weeks following transplantation (e); GST $\pi$-labeled cells were seen to migrate widely in the striatum (e) and into adjacent white matter tracts (not shown). Neural precursor-derived astrocytes expressing human GFAP shown here in the contralateral striatum emerging from the corpus callosum (f). $\mathrm{TH}$-immunoreactive cells seen transiently within a low-density graft at 6 weeks (g). Scale bars: $500 \mu \mathrm{m}$ (a, b, e); $250 \mu \mathrm{m}$ (c, d); $50 \mu \mathrm{m}$ (f, g). 
Proliferative Profile of Transplanted HNPCs Using Human-Specific Ki-67

Staining for the human proliferation marker Ki-67, which is expressed during all active phases of the cell cycle $(33,34)$, revealed that expanded populations of human neural precursors will express $\mathrm{Ki}-67$ in vitro. A number of these cells also expressed $\beta$-tubulin-III indicating that human neuronal progenitors were dividing, as seen previously for rodent neuronal progenitors derived from embryonic and postnatal neural tissue (3, 8, 39). Previous studies have demonstrated neurohistogenesis following transplantation of embryonic neocortex into the adult cerebellum (17). Lundberg and colleagues indicated that immortalized neural stem cells would also undergo two or three divisions during the first week following transplantation into the rat striatum (38). Similarly, Isenmann and co-workers showed that approximately $35 \%$ of transplanted primary mouse telencephalic cells were undergoing proliferation at 1-3 days after grafting into the striatum, although the number of cells dividing after 40 days had reduced to less than $1.6 \%$ (31). In the present study, we have shown that up to $30 \%$ of transplanted HNPCS were still dividing at 2 weeks following grafting. Interestingly, we noticed an inverse relationship between the proportion of dividing cells and the density of the transplant. This would indicate that accessibility of grafted cells to host-derived factors (required to sustain cell division) might be limited by the density of the transplant. By 6 weeks following transplantation, a small proportion of the grafted cells located in the host striatum also expressed human $\mathrm{Ki}-67$, thus indicating that migrating HNPCs are capable of division. However, in all transplants, virtually no dividing cells could be found at 20 weeks. In support of these observations, we found no evidence of excessive cell proliferation, tissue overgrowth, or tumor formation in any of the recipient brains.

\section{HNPCs Expanded in Culture Retain the Capacity to \\ Project Long Axons into the Host CNS}

Long-distance axonal outgrowth following transplantation of human neural tissue into the adult rodent brain has been demonstrated previously only for grafts of nonexpanded primary neuroblasts derived from the embryonic telencephalon (60) and ventral mesencephal on (61). We, and others, have shown that while expanded HNPCs can survive transplantation into the lesioned or intact adult brain, such cells generally migrate widely without forming a significant graft mass or generating extensive neurite outgrowth $(21,44,48,49,55)$. In contrast, the present study has shown, for the first time, that expanded HNPCs can elaborate extensive efferent connections to the CNS over a time scale similar to that seen for primary neuroblasts. This may reflect modifications to our transplantation protocol; these included omission of bromodeoxyuridine labeling, which has been shown to be toxic to newly generated neurons $(4,36)$, and the transplantation of small intact neurospheres. The demonstration of extensive axonal outgrowth does not, however, indicate synaptogenesis and further studies are required at the electron microscopic level to ascertain the extent and type of connections generated by these cells.

The Number of Cells Transplanted Has a Significant

Effect on Graft Survival-More Cells Is N ot Always Better

A density-dependent survival of genetically modified FGF-2-responsive human precursor cells has been reported following intrastriatal grafting where cell densities less than 1 million did not result in viable transplants (44). The suggestion was that unless high densities of HNPCs are used, graft survival would be poor. However, in contrast, the present study demonstrates that small grafts can, in fact, extend many fibers into the host CNS and may provoke less of an immune response than larger grafts. Very high-density grafts (2 million cells) in the present model system provided little evidence of neuronal differentiation and fiber outgrowth, suggesting the existence of an upper limit to the number of transplanted cells sustainable by either host-derived or graft-derived factors. Whether the same considerations would apply following transplantation of equivalent human cell densities into the lesioned primate striatum remains to be determined. A further issue, however, relates to the xenotypic nature of the present transplantation paradigm and graft rejection. While it is not possible to comment on the extent to which humoral and complement-mediated factors play a role in neural xenograft rejection, our data would suggest that a host-derived T-cell-mediated immunological response represents a major determinant in this process, as previously suggested for other model systems $(9,29,41)$. Future experiments might therefore be directed toward studying the induced expression of major histocompatibility complex (MHC) class I and class II antigens in the host adult brain and in the grafted xenogeneic tissue. It is also recognized that CD4 T-lymphocytes and microglia play a major role in the recognition and rejection of primary xenografts $(18,41,62)$, and further studies are required to establish whether similar mechanisms are operational in the rejection of HNPC xenografts. As might be expected, given the large number of MHC haplotypes for a population of out-bred rats, we observed considerable heterogeneity of the immunological response among the grafted brains. Interestingly, however, the most florid signs of graft rejection were seen in recipients of high-density grafts. The reasons for this remain unclear, although one can speculate that the large antigenic stimulus presented by high-density transplants, coupled with a greater degree of blood-brain barrier 
disruption and inflammation at the time of surgical implantation, would be more likely to elicit an immune response from the host.

\section{Unpredictable Spontaneous TH Expression in HNPC- Derived Neurons}

The expression of human GST $\pi$ and GFAP indicates that a substantial proportion of glia arising from grafted HNPCs had migrated widely throughout the adult striatum and into adjacent white matter tracts, consistent with previous reports $(21,48,49)$. These findings further conform to the view that transplanted glial precursors are capable of proliferation and migration within the adult CNS $(6,12)$. TH-expressing neurons were only found transiently within the intrastriatal grafts at 6 weeks. This would suggest that the lesioned adult striatum retains at least some of the endogenous cues required to support the development of dopaminergic neurons from undifferentiated HNPCS and is in agreement with our earlier investigations (48, 49). However, in the present study no TH neurons could be found at 20 weeks postgrafting. Clearly, the induction of $\mathrm{TH}$ expression is a stochastic and unpredictable event in these transplants, the mechanism for which requires further experiments. Recent studies have shown that $\mathrm{TH}$ expression in neural precursor cells can be induced by the transcription factor Nurr 1 $(45,57)$ and suggest that it may soon be possible to genetically modify these HNPCs to produce dopamine prior to transplantation.

\section{ACKN O WLEDG MENTS}

These studies were supported by Wellcome Trust Research Fellowships (T.O. and C.N.S.), The Raymond and Beverly Sackler Trust (T.O.), and an MSD Research Fellowship (M.A.C.).

\section{REFERENCES}

1. Allsopp, R. C., E. Chang, M. Kashefi-Aazam, et al. 1995. Telomere shortening is associated with cell division in vitro and in vivo. Exp. Cell Res. 220: 194-200.

2. Alvarez-Buylla, A., and S. Temple. 1998. Stem cells in the developing and adult nervous system. J . Neurobiol. 36: 105110.

3. Arsenijevic, Y., and S. Weiss. 1998. Insulin-like growth factor-1 is a differentiation factor for postmitotic CNS stem cell-derived neuronal precursors: Distinct actions from those of brain-derived neurotrophic factors. J . Neurosci. 18: 2118-2128.

4. Biggers, W. J ., E. R. Barnea, and M. K. Sanyal. 1987. Anomalous neural differentiation induced by 5-bromo- 2 '-deoxyuridine during organogenesis in the rat. Teratology 35: 63-75.

5. Björklund, A., and U. Stenevi. 1979. Reconstruction of the nigrostriatal dopamine pathway by intracerebral nigral transplants. Brain Res. 177: 555-560.

6. Blakemore, W. F., and R.J . M. Franklin. 1991. Transplantation of glial cells into the CNS. Trends Neurosci. 14: 323-327.

7. Bodnar, A. G., M. Ouellette, M. Frolkis, et al. 1998. Extension of life-span by introduction of telomerase into normal human cells. Science 279: 349-352.
8. Brock, S. C., J. Bonsall, and M. B. Luskin. 1998. The neuronal progenitor cells of the forebrain subventricular zone: Intrinsic properties in vitro and following transplantation. Methods 16: 268-281.

9. Brundin, P., O. G. Nilsson, F. H. Gage, and A. Bjorklund. 1985. Cyclosporin A increases survival of cross-species intrastriatal grafts of embryonic dopamine-containing neurons. Exp. Brain Res. 60: 204-208.

10. Brüstle, O. 1999. Building brains: Neural chimeras in the study of nervous system development and repair. Brain Pathol. 9: 527-545.

11. Brüstle, O., K. Choudhary, K. Karram, et al. 1998. Chimeric brains generated by intraventricular transplantation of fetal human brain cells into embryonic rats. Nat. Biotechnol. 16: 1040-1044.

12. Burke, J.F., and P. J. Benson. 1997. Neuronal and glial cell biology/disease transplantation and regeneration. Curr. Opin. Neurobiol. 7: 593.

13. Campisi, J . 1996. Replicative senescence: An old lives' tale. Cell 84: 497-500.

14. Carpenter, M. K., X. Cui, Z. Y. Hu, et al. 1999. In vitro expansion of a multipotent population of human neural progenitor cells. Exp. Neurol. 158: 265-278.

15. Counter, C. M., A. A. Avilion, C. E. LeFeuvre, et al. 1992. Telomere shortening associated with chromosome instability is arrested in immortal cells which express telomerase activity. EMBO J. 11: 1921-1929.

16. Coviello-McLaughlin, G. M., and K. R. Prowse. 1997. Telomere length regulation during postnatal development and ageing in Mus spretus. Nucleic. Acids Res. 25: 3051-3058.

17. Das, G. D., and D. T. Ross. 1986. Neural transplantation: Autoradiographic analysis of histogenesis in neocortical transplants. Int. J . Dev. Neurosci 4: 69-79.

18. Duan, W. M., H. Widner, and P. Brundin. 1995. Temporal pattern of host responses against intrastriatal grafts of syngeneic, allogeneic or xenogeneic embryonic neuronal tissue in rats. Exp. Brain Res. 104: 227-242.

19. Dunnett, S. B., W. C. Low, S. D. Iversen, et al. 1982. Septal transplants restore maze learning in rats with fornix-fimbria lesions. Brain Res. 251: 335-348.

20. Flax, J. D., S. Aurora, C. Yang, et al. 1998. Engraftable human neural stem cells respond to developmental cues, replace neurons, and express foreign proteins. Nat. Biotechnol. 16: 10331039.

21. Fricker, R. A., M. K. Carpenter, C. Winkler, et al. 1999. Sitespecific migration and neuronal differentiation of human neural progenitor cells after transplantation in the adult rat brain. J . Neurosci. 19: 5990-6005.

22. Goldstein, S. 1990. Replicative senescence: The human fibroblast comes of age. Science 249: 1129-1133.

23. Hahn, W. C., C. M. Counter, A. S. Lundberg, et al. 1999. Creation of human tumour cells with defined genetic elements. Nature 400: 464- 468.

24. Harley, C. B. 1991. Telomere loss: Mitotic clock or genetic time bomb? Mutat. Res. 256: 271-282.

25. Harley, C. B., A. B. Futcher, and C. W. Greider. 1990. Telomeres shorten during ageing of human fibroblasts. Nature 345: 458- 460.

26. Harley, C. B., N. W. Kim, K. R. Prowse, et al. 1994. Telomerase, cell immortality, and cancer. Cold Spring Harbor Symp. Quant. Biol. 59: 307-315.

27. Hayflick, L., and P. S. Moorhead. 1961. The serial cultivation of human diploid cell strains. Exp. Cell Res. 25: 585- 621.

28. Hoffer, B. J., and L. Olson. 1991. Ethical issues in brain-cell transplantation. Trends Neurosci. 14: 384-388. 
29. Inoue, H., S. Kohsaka, K. Yoshida, et al. 1985. Cyclosporin A enhances the survivability of mouse cerebral cortex grafted into the third ventricle of rat brain. Neurosci. Lett. 54: 85-90.

30. I sacson, O. 1999. The neurobiology and neurogenetics of stem cells. Brain Pathol. 9: 495- 498.

31. Isenmann, S., S. Brandner, U. Sure, and A. Aguzzi. 1996. Telencephalic transplants in mice: Characterization of growth and differentiation patterns. Neuropathol. Appl. Neurobiol. 22: 108-117.

32. Kendall, A. L., F. D. Rayment, E. M. Torres, et al. 1998. Functional integration of striatal allografts in a primate model of Huntington's disease. Nature Med. 4: 727-729.

33. Kill, I. R. 1996. Localisation of the Ki-67 antigen within the nucleolus: Evidence for a fibrillarin-deficient region of the dense fibrillar component. J . Cell Sci. 109: 1253-1263.

34. Kill, I. R., R. G. A. Faragher, K. Lawrence, and S. Shall. 1994. The expression of proliferation-dependent antigens during the lifespan of normal and progeroid human fibroblasts in culture. J. Cell Sci. 107: 571-579.

35. Kim, N. W., M. A. Piatyszek, K. R. Prowse, et al. 1994. Specific association of human telomerase activity with immortal cells and cancer. Science 266: 2011-2015.

36. Kolb, B., B. Pedersen, M. Ballermann, et al. 1999. Embryonic and postnatal injections of bromodeoxyuridine produce agedependent morphological and behavioral abnormalities. J . Neurosci. 19: 2337-2346.

37. Lindvall, O. 1998. Update on fetal transplantation: The Swedish experience. Mov. Disord. 13(Suppl 1): 83-87.

38. Lundberg, C., A. Martinez-Serrano, E. Cattaneo, et al. 1997. Survival, integration, and differentiation of neural stem cell lines after transplantation to the adult rat striatum. Exp. Neurol. 145: 342-360.

39. Luskin, M. B., T. Zigova, B. J . Soteres, and R. R. Stewart. 1997. Neuronal progenitor cells derived from the anterior subventricular zone of the neonatal rat forebrain continue to proliferate in vitro and express a neuronal phenotype. Mol. Cell. Neurosci. 8: 351-366.

40. McKay, R. 1997. Stem cells in the central nervous system. Science 276: 66-71.

41. Pakzaban, P., and O. I sacson. 1994. Neural xenotransplantation: Reconstruction of neuronal circuitry across species barriers. Neuroscience 62: 989-1001.

42. Perlow, M.J ., W. J . Freed, B. J . Hoffer, A. Seiger, L. Olson, and R. J. Wyatt. 1979. Brain grafts reduce motor abnormalities produced by destruction of nigrostriatal dopamine system. Science 204: 643- 647.

43. Reynolds, B. A., W. Tetzlaff, and S. Weiss. 1992. A multipotent EGF-responsive striatal embryonic progenitor cell produces neurons and astrocytes. J . Neurosci. 12: 4565- 4574.

44. Sabaté, O., P. Horellou, E. Vigne, et al. 1995. Transplantation to the rat brain of human neural progenitors that were genetically modified using adenoviruses. Nat. Genet. 9: 256-260.

45. Sakurada, K., M. Ohshima-Sakurada, et al. 1999. Nurr1, an orphan nuclear receptor, is a transcriptional activator of endogenous tyrosine hydroxylase in neural progenitor cells derived from the adult brain. Devel opment 126: 4017- 4026.

46. Shay, J. W., and S. Bacchetti. 1997. A survey of telomerase activity in human cancer. Eur. J . Cancer 33: 787-791.

47. Svendsen, C. N., M. A. Caldwell, and T. Ostenfeld. 1999. Human neural stem cells: Isolation, expansion and transplantation. Brain Pathol. 9: 499-513.
48. Svendsen, C. N., M. A. Caldwell, J. Shen, et al. 1997. Long-term survival of human central nervous system progenitor cells transplanted into a rat model of Parkinson's disease. Exp. Neurol. 148: 135-146.

49. Svendsen, C. N., D. J . Clarke, A. E. Rosser, and S. B. Dunnett. 1996. Survival and differentiation of rat and human epidermal growth factor-responsive precursor cells following grafting into the lesioned adult central nervous sytem. Exp. Neurol. 137: 376-388.

50. Svendsen, C. N., J . W. Fawcett, C. Bentlage, and S. B. Dunnett. 1995. Increased survival of rat EGF-generated CNS precursor cells using B27 supplemented medium. Exp. Brain Res. 102: 407- 414.

51. Svendsen, C. N., J . Skepper, A. E. Rosser, et al. 1997. Restricted growth potential of rat neural precursors as compared to mouse. Dev. Brain Res. 99: 253-258.

52. Svendsen, C. N., and A. G. Smith. 1999. Human stem cell therapy. Trends Neurosci. 22: 357-364.

53. Svendsen, C. N., M. G. ter Borg, R. J . E. Armstrong, et al. 1998. A new method for the rapid and long term growth of human neural precursor cells. J . Neurosci. Methods 85: 141-152.

54. Thomson, J. A., J . Itskovitz-Eldor, S. S. Shapiro, et al. 1998. Embryonic stem cell lines derived from human blastocysts. Science 282: 1145-1147.

55. Vescovi, A. L., E. A. Parati, A. Gritti, et al. 1999. I solation and cloning of multipotential stem cells from the embryonic human CNS and establishment of transplantable human neural stem cell lines by epigenetic stimulation. Exp. Neurol. 156: 71- 83.

56. Vescovi, A. L., and E. Y. Snyder. 1999. Establishment and properties of neural stem cell clones: Plasticity in vitro and in vivo. Brain Pathol. 9: 569-598.

57. Wagner, J ., P. Kerud, D. S. Castro, et al. 1999. Induction of a midbrain dopaminergic phenotype in Nurr1-overexpressing neural stem cells by type 1 astrocytes. Nature Biotechnol. 17: 653- 659.

58. Watson, J. D. 1972. Origin of concatemeric T7 DNA. Nat. New Biol. 239: 197-201.

59. West, M. J., L. Slomianka, and H. J. G. Gundersen. 1991. Unbiased stereological estimation of the total number of neurons in the subdivisions of the rat hippocampus using the optical fractionator. Anat. Rec. 231: 482- 497.

60. Wictorin, K., P. Brundin, B. Gustavii, et al. 1990. Reformation of long axon pathways in adult rat central nervous system by human forebrain neuroblasts. Nature 347: 556-558.

61. Wictorin, K., P. Brundin, H. Sauer, et al. 1992. Long distance directed axonal growth from human dopaminergic mesencephalic neuroblasts implanted along the nigrostriatal pathway in 6-hydroxydopamine lesioned adult rats. J. Comp. Neurol. 323: 475- 494.

62. Wood, M. J ., D. J . Sloan, K. J . Wood, and H. M. Charlton. 1996. Indefinite survival of neural xenografts induced with anti-CD4 monoclonal antibodies. Neuroscience 70: 775-789.

63. Wynford-Thomas, D. 1996. Telomeres, p53 and cellular senescence. Oncol. Res. 8: 387-398.

64. Yoshimi, N., N. I no, M. Suzui, et al. 1996. Telomerase activity of normal tissues and neoplasms in rat colon carcinogenesis induced by methylazoxymethanol acetate and its difference from that of human colonic tissues. Mol. Carcinog. 16: 1-5. 